\title{
Study of the Textural Properties of Bovine Bones Char under Different Conditions
}

\author{
Juan C. Moreno-Piraján ${ }^{1}$, Liliana Giraldo ${ }^{2}$, Vanessa S. García-Cuello ${ }^{1}$ \\ ${ }^{1}$ Grupo de Investigación en Sólidos Porosos y Calorimetría, Departamento de Química, Facultad de Ciencias. \\ Universidad de los Andes. Bogotá, Colombia \\ ${ }^{2}$ Departamento de Química, Facultad de Ciencias. Universidad Nacional de Colombia. Bogotá, Colombia \\ E-mail: jumoreno@uniandes.edu.co \\ Received January 3, 2011; revised February 6, 2011; accepted March 1, 2011
}

\begin{abstract}
Environmental pollution is today a very important issue and the development of low cost materials and different sources need to be investigated. Our research group for several years she has been the development of adsorbent materials for industrial wastewater treatment and rivers. In this research compares the porosity developed by two different treatments using bovine bones to adsorb metal ions. Using bovine bones as raw material, two carbonized samples were obtained under different conditions. One of the carbonized samples was obtained in an oxidizing atmosphere at up to $600^{\circ} \mathrm{C}$ for 2 hours. The other was obtained in an inert atmosphere at up to $800^{\circ} \mathrm{C}$, during 2 hours. Different textural characteristics were obtained in each of the carbonized samples according to the conditions of synthesis. The carbonized sample obtained in the oxidizing atmosphere, CHUOX, produces a great pore distribution, with a significant mesopore volume, reflected in the hysteresis loop, while in carbonized bone obtained in an inert atmosphere, CHUN, a formation of micropores and mesopores smaller than that obtained in the other carbonized sample is observed. The surface area obtained is $130 \mathrm{~m}^{2} \cdot \mathrm{g}^{-1}$ for CHUOX and $170 \mathrm{~m}^{2} \cdot \mathrm{g}^{-1}$ for CHUN. Furthermore, the adsorption capacity of $\mathrm{Ni}^{2+}$ and $\mathrm{Cu}^{2+}$ ions from solution was measured for these two carbonized samples, and a higher retention of both ions in the carbonized sample obtained in the inert atmosphere was found, with values between 28.57 and $67.56 \mathrm{mg} \cdot \mathrm{g}^{-1}$. The immersion enthalpies of carbonized samples in ion solutions are determined with an exothermic effect for the solution-solid interaction.
\end{abstract}

Keywords: Adsorption, Heavy Metals, Water, Immersion Calorimetry, Bovine Bone

\section{Introduction}

Recently, the attention has also been paid to the application of sorbents from agricultural and forestry sources, since the cost of these materials is much lower than the cost of commercial adsorbents, such as activated carbon or ion-exchange resins [1].

Extensive research has been carried out during the last ten years to find low-cost, high capacity adsorbents for the removal of metal ions. A wide range of adsorbents have been developed and tested, including several activated carbons [2]. A number of low-cost agricultural wastes; mud tire rubber and fly ash have been used for the removal of a range of metal ions. Other minerals and materials with potential for exchange sorption with copper and nickel been tested; among those are sodium calcium bentonite and bone char [3]. Sorbents that might gain some interest in the future are materials of plant or animal origin, as animal bones. The animal bones are composed in $65 \%-70 \%$ of inorganic substances, mainly hydroxyapatite. The chemical composition of hydroxyapatite is $\mathrm{Ca}_{10}\left(\mathrm{PO}_{4}\right)_{6}(\mathrm{OH})_{2}$. The remaining part of bones is composed of organic matter, mainly fibrous protein collagen [4].

Copper and nickel are among the most toxic metals affecting the enviromnent. Many studies have shown that these metals are toxic even at very low concentrations. However, these metals have many applications in the industrial life. For example, copper is known as an excellent conductor of electricity and is widely used in the electro-industry in all gauges of wires fat circuitry. It is also utilized in analytical reagents, in paints for ships' bottoms and in electroplating but it acts as an irritant to the skin causing itching and dermatitis, and may cause 
kertinization of the hands and soles of the feet [5].

Having in mind the adverse effects of heavy metals, environmental agencies set permissible limits for their levels in drinking water and other types of waters. For example, according to the World Health Organization guidelines for drinking water, the permissible levels of $\mathrm{Cu}^{2+}$ and $\mathrm{Ni}^{2+}$ are 1.0 and $5 \mathrm{mg} \cdot \mathrm{L}^{-1}$, respectively [6].

There is a search for low cost adsorbent materials with the capacity to adsorb heavy metals from water, given their continuing toxicity, and knowledge of the adsorption process means that this could be carried out in a more efficient way and that the conditions could be controlled in order to adsorb a larger quantity of the metallic ions.

For this the characterization of the solid's properties and the form in which it interacts with the ions that it tries to withdraw from the water is carried out [7].

The immersion calorimetry is used to determine, depending on the thermodynamic conditions of the system, the heat that is produced when the solid and a liquid make contact and therefore the immersion enthalpy of the contact process which is established for a specific quantity of the solid studied [8].

The intensity of the interaction between the solution and the activated carbon can be determined by means of the immersion enthalpy of the solid in solutions that contain active substances that react with the surface and that allow the physicochemical properties of the activated carbon to be related to the adsorption capacity of the compounds in solution [9].

In this work adsorbent material samples are prepared from bovine bones in inert and oxidizing atmospheres which are characterized by means of gas adsorption and are used in the $\mathrm{Cu}^{2+}$ and $\mathrm{Ni}^{2+}$ adsorption from aqueous solution, whose behavior is described by means of the adsorption isotherms; the immersion enthalpies of concentrations of the metallic ion are also determined and are compared to the maximum quantities adsorbed, determined by the Langmuir model, with the immersion enthalpies.

\section{Materials and Methods}

\subsection{Preparation of the Activated Carbon}

The reactor is a $45 \mathrm{~mm}$ (i.d.) stainless steel cylindrical pipe surrounded by a ceramic insulation layer. Energy required for the process is provided by a $5 \mathrm{~kW}$ heating coil which is embedded in the ceramic insulation. A quartz mesh basket is connected to a mass balance via a ceramic rod and suspended in the hot zone of the reactor. Both the inlet and exit pipes to the reactor are heated to prevent condensation of the gases generated. Temperature is controlled via a thermocouple linked to a PID temperature controller.

Cow bone was charged into the quartz basket. During pyrolysis, nitrogen gas was introduced by the bottom of the reactor to provide an inert atmosphere. Samples were pyrolysed at a heating rate of $10^{\circ} \mathrm{C} / \mathrm{min}$ until the predetermined temperature $\left(600^{\circ} \mathrm{C}\right)$ was reached and held at that constant temperature for a specific hold time. Exit gases leaving the reactor were cooled to room temperature using ice as the cooling medium. Wastes were trapped to remove tars and other matter produced in this process. This char activated of cow bone is produced with a rudimentary pore structure in the quartz basket. One portion of the resultant chars of activated cow bone obtained this way is subjected to partial oxidation with a mixture of oxygen/nitrogen (30/80). Gas mixture enters reactor by bubbling through a set of bottles that kept of constant temperature of $800^{\circ} \mathrm{C}$ during 5 hours with a heating rate of $3{ }^{\circ} \mathrm{C} \cdot \mathrm{min}^{-1}$ and an $\mathrm{N}_{2}$ flow of $80 \mathrm{~cm}^{3}$. $\min ^{-1}$. Gases exiting reactor during this stage followed the same route as in the pyrolysis process. Bone cow activated carbon left behind in the reactor was cooled with nitrogen gas current to room temperature before being removed. This sample was labeled CHUN.

The material prepared in air atmosphere, (was labeled CHUOX), was treated thermally in a cubic oven to a temperature of $600^{\circ} \mathrm{C}$ for 2 hours.

\subsection{Textural Characterization of Bovine Bone Carbonized}

The characterization of bovine bones chars samples was carried out using $\mathrm{N}_{2}$ adsorption at $77 \mathrm{~K}$ using Quantachrome Autosorb 3B (Boynton Beach, FL, USA) surface area analyzer to assess the pore morphology of the produced chars. Samples were previously outgassed at 250 ${ }^{\circ} \mathrm{C}$ for several hours. The BET surface area, micropore and total pore volume, and pore size distribution were obtained by analyzing $\mathrm{N}_{2}$ adsorption. The specific surface areas were determined according to the BET method at the relative pressure in the range of $0.05-0.30$. Pore volume was directly calculated from the volume of nitrogen held at the highest relative pressure $\left(p / p^{0}=0.99\right)$.

\subsection{Adsorption Equilibrium Isotherm}

Batch sorption experiments were conducted using 100 $\mathrm{mL}$ aliquots of $\mathrm{pH}$ adjusted test solutions containing 100 $\mathrm{mg} \cdot \mathrm{L}^{-1}$ of each one of the ions $\mathrm{Ni}^{2+}$ and $\mathrm{Cu}^{2+}$ in monocomponent systems and placed in $250 \mathrm{~mL}$ amber closed bottles. A known quantity $(0.01-0.15 \mathrm{~g})$ of carbonized solid, CHUN or CHUOX, was added to each bottle. Solutions were stirred at $200 \mathrm{rpm}$ for 2 hours at $(25 \pm 1)^{\circ} \mathrm{C}$. The bone carbonized was removed by filtration and the $\mathrm{Ni}^{2+}$ and $\mathrm{Cu}^{2+}$ concentrations were measured by atomic 
absorption spectroscopy, in a Perkin Elmer AAnalyst equipment, at the end of each time period. Blank solutions were also prepared and analyzed. The $\mathrm{pH}$ values of each metal ion solution were adjusted using either 0.01 $\mathrm{M} \mathrm{NaOH}$ or $0.01 \mathrm{M} \mathrm{HNO}_{3}$ solutions and the volumes used were recorded to calculate the final solution volume.

\subsection{Immersion Enthalpy}

Immersion enthalpies of bovine bone carbonized, CHUN and CHUOX, were determined in $\mathrm{Ni}^{2+}$ and $\mathrm{Cu}^{2+}$ solutions at a concentration of $100 \mathrm{mg} \cdot \mathrm{L}^{-1}$ for the maximum adsorption $\mathrm{pH}$ of 5 . This determination was performed in a heat conduction microcalorimeter equipped with a stainless steel calorimetric cell $[9,10]$. Thirty $\mathrm{mL}$ of the solution to be used were pre-heated at $25^{\circ} \mathrm{C}$, and then placed in the cell. A sample of approximately $0.500 \mathrm{~g}$ of solid was weighed and placed inside the calorimetric cell in a glass ampoule. The microcalorimeter was then assembled. When the equipment reached the temperature of $25^{\circ} \mathrm{C}$, potential readings were registered after a period of approximately 15 minutes, with readings every 20 seconds, the glass ampoule was broken and the generated thermal effect recorded. Electric potential readings were continuing for approximately 15 minutes more and at the end of the experiment, the equipment was electrically calibrated [10].

\section{Results and Discussion}

Figure 1 shows the $\mathrm{N}_{2}$ adsorption isotherms at $-196{ }^{\circ} \mathrm{C}$ obtained for carbonized bovine bone, CHUN and CHOX. The nitrogen adsorption for both samples is similar at relative pressures up to 0.5 , with a volume between 35 and $50 \mathrm{~cm}^{3} \cdot \mathrm{g}^{-1}$ being adsorbed. At relative pressures superior to 0.5 the presence of loops is observed when the adsorbate desorption is realized, indicating a porosity of major size.

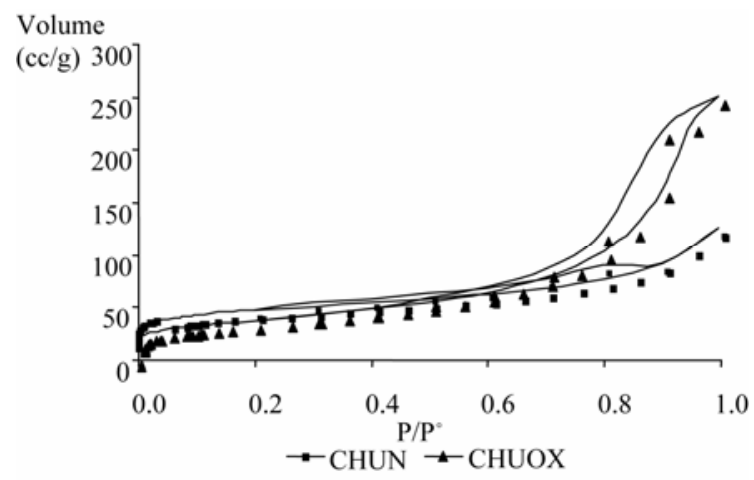

Figure 1. $\mathrm{N}_{2}$ adsorption isotherms of carbonized bovine bone at $-196^{\circ} \mathrm{C}$.
The bovine bones char prepared by physical activation with nitrogen and in air gives a type IV isotherm, but in this case a plateau is not clearly reached, indicating widening of pores; this isotherm exhibits an $\mathrm{H}_{4}$ type hysteresis loop, characteristic of slit-shaped pores.

Table 1 presents the results of characterizations of the two carbonized samples, calculated from the adsorption isotherms.

The results indicate that the thermal treatment that is realized on the bovine bone produces solid with a larger superficial area of $170 \mathrm{~m}^{2} \cdot \mathrm{g}^{-1}$ when using a nitrogen atmosphere than when the atmosphere is air, and this is also reflected in the pore volume values. As for the values obtained for the average pore diameter, the same value of $6.6 \mathrm{~nm}$ is obtained for the two carbonized samples.

Once the bones had been carbonized in the conditions mentioned, their structure was observed by scanning electronic microscopy in a JEOL model JSM 6490-LV equipment. Figure 2 corresponds to the photograph taken of the carbonized CHUOX, and it is observed that this presents irregularities in the surface, with interconnected pores, and the presence of wide porosity and heterogeneity is shown. The big orifices that appear in Figure 2 have approximate dimensions of $260 \mu \mathrm{m}$.

Figure 3 presents the obtained infrared spectrum of the carbonized $\mathrm{CHUN}$, in which the vibrations of the observed phosphate, $\mathrm{PO}_{4}^{3-}$, follow peaks corresponding to: asymmetric stretching of the $\mathrm{P}-\mathrm{O}$ link at $1091 \mathrm{~cm}^{-1}$ and $1046 \mathrm{~cm}^{-1}, \mathrm{O}-\mathrm{P}-\mathrm{O}$ clipping at $568 \mathrm{~cm}^{-1} \mathrm{y}$ and 602 $\mathrm{cm}^{-1}$, and $\mathrm{O}-\mathrm{H}$ bands of tension at $3424 \mathrm{~cm}^{-1}$. These bands are typical of the composition of the raw material, which is constituted principally of hydroxyapatite, which has a chemical composition is $\mathrm{Ca}_{10}\left(\mathrm{PO}_{4}\right)_{6}(\mathrm{OH})_{2}$ and is the main inorganic constituent of bone tissues in all ver-

Table 1. Textural characteristics of carbonized bovine bone.

\begin{tabular}{lcc}
\hline \multicolumn{1}{c}{ Property } & CHUOX & CHUN \\
\hline Surface area B.E.T $\left(\mathrm{m}^{2} \cdot \mathrm{g}^{-1}\right)$ & 170 & 130 \\
Volume pore $\left(\mathrm{cm}^{3} \cdot \mathrm{g}^{-1}\right)$ & 1.23 & 0.53 \\
Average diameter pore $(\mathrm{nm})$ & 6.6 & 5.9 \\
\hline
\end{tabular}

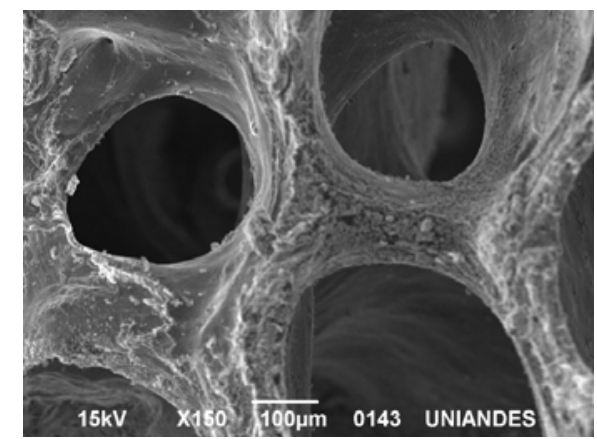

Figure 2. SEM microphotograph. Partial view of carbonized CHUOX surface. Magnification: $\times 150$. 


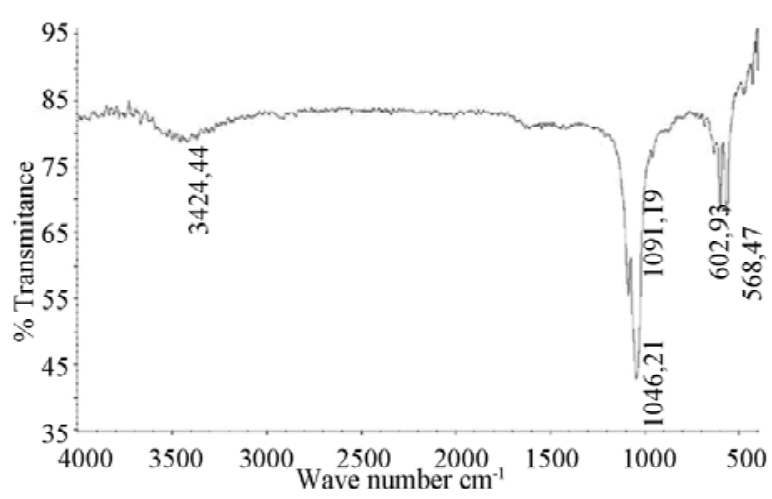

Figure 3. IR for the bovine bone carbonized CHUN.

tebrates [4].

Once the carbonized samples are characterized texturally they are used in the $\mathrm{Cu}^{2+}$ and $\mathrm{Ni}^{2+}$ ions adsorption from aqueous solution, with the $\mathrm{pH}$ adjusted to a value of 5 as suggested by Porter et al. [11], since this is the $\mathrm{pH}$ at which maximum adsorption occurs when the adsorbents come from animal bones.

The adsorption isotherms are determined for both ions in each of the carbonized samples which appear in Figures $4 \mathbf{a}$ and $\mathbf{4 b}$.

Figure 4a presents the isotherms obtained for the $\mathrm{Cu}^{2+}$ and $\mathrm{Ni}^{2+}$ ions adsorption from the carbonized samples obtained in inert atmosphere, CHUOX. It is observed that the adsorption for the $\mathrm{Cu}^{2+}$ is greater that for the $\mathrm{Ni}^{2+}$ at approximately $20 \mathrm{mg} \cdot \mathrm{g}^{-1}$, which relates to a major interaction of the copper ion with the solid. When the values of the ionic radiuses of both ions are compared they are found to be 0.69 and $0.78 \AA$ for the $\mathrm{Cu}^{2+}$ and $\mathrm{Ni}^{2+}$ respectively, and as the ion copper is smaller it will have greater contact with the carbonized sample.

Figure $\mathbf{4 b}$ presents the adsorption isotherms of both ions from aqueous solution in the carbonized CHUN. The behavior is similar to the previous one, with greater adsorption for the $\mathrm{Cu}^{2+}$ than for the $\mathrm{Ni}^{2+}$; nevertheless the adsorbed quantities are minor for this carbonized sample in comparison to the carbonized CHUOX, presenting a smaller value of surface area, which indicates the relation between the adsorption of the ions and the surface developed in the solid. We believe that according to the composition of the bones and previous work by our research group, the adsorption of ions carried by both ion exchange and adsorption.

Figure 5 shows the lines obtained when the experimental data are fitted to the Langmuir model.

Is observed that on fitting the adsorption isotherm data of the ions to the Langmuir model, straight lines are obtained, from which the values of the maximum quantity adsorbed in the monolayer, $\mathrm{X}_{\mathrm{m}}$, and the adsorption process constant, $\mathrm{K}_{\mathrm{L}}$, can be obtained. The lines for the adsorption of $\mathrm{Ni}^{2+}$ in the carbonized CHUOX and for the

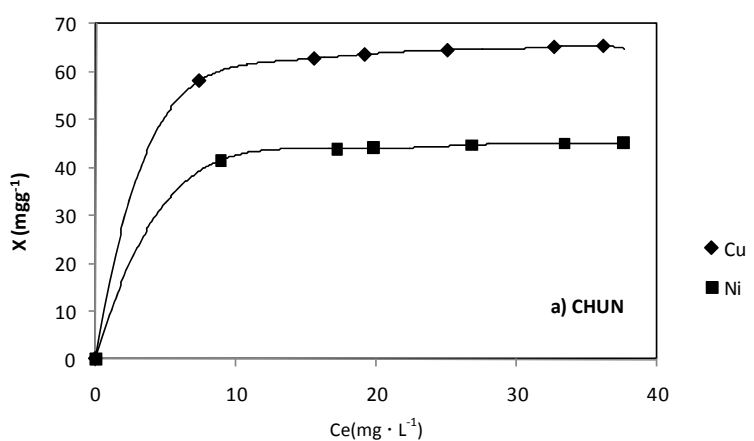

(a)

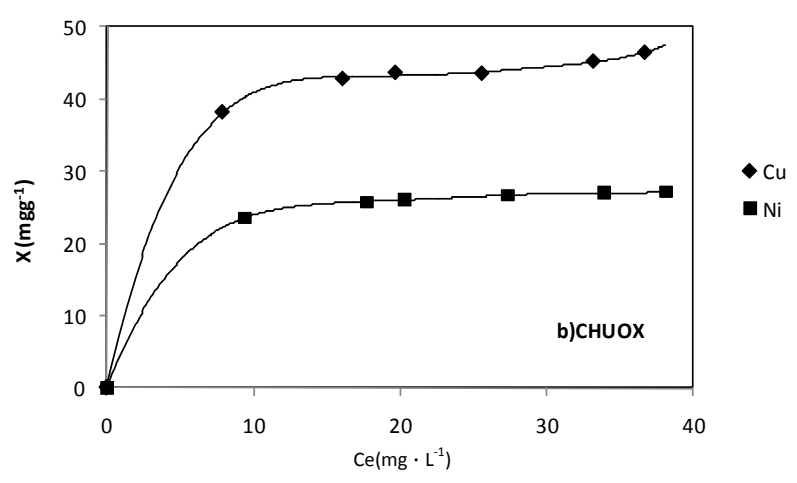

(b)

Figure 4. $\mathrm{Cu}^{2+}$ and $\mathrm{Ni}^{2+}$ adsorption isotherms from aqueous solution in a) carbonized CHUOX b) carbonized CHUN.

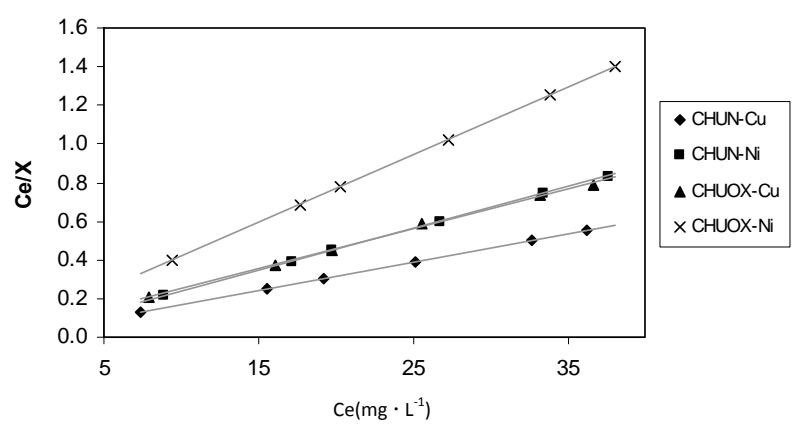

Figure 5. Langmuir model. Linearization of the experimental data.

$\mathrm{Cu}^{2+}$ in the carbonized CHUN are similar provided that the quantities adsorbed in the monolayer have similar values. Table 2 shows the results obtained for the adsorption of both ions in the carbonized samples, fitting the data to the Langmuir model.

The capacity adsorption of activated carbons from bovine bone is really good and in many cases exceeds the adsorption capacity of these same ions obtained with other materials such as cloth activated carbon cloth and granular activated carbon obtained from lignocellulosic residues [12].

Further, the intensity of the interaction between the 
Table 2. Langmuir model constants in the $\mathrm{Cu}^{2+}$ and $\mathrm{Ni}^{2+}$ adsorption in carbonized bovine bones.

\begin{tabular}{clcc} 
& \multicolumn{1}{c}{ Parameter } & CHUOX & CHUN \\
\cline { 2 - 4 } $\mathrm{Cu}^{2+}$ & $\mathrm{Xm}\left(\mathrm{mg} \cdot \mathrm{g}^{-1}\right)$ & 67.56 & 48.78 \\
& $\mathrm{~K}_{\mathrm{L}}\left(\mathrm{gL}^{-1}\right)$ & 0.83 & 0.51 \\
& $\mathrm{R}$ & 0.9992 & 0.9995 \\
& $\mathrm{Xm}\left(\mathrm{mg} \cdot \mathrm{g}^{-1}\right)$ & 46.29 & 28.57 \\
$\mathrm{Ni}^{2+}$ & $\mathrm{K}_{\mathrm{L}}\left(\mathrm{gL}^{-1}\right)$ & 0.96 & 0.51 \\
& $\mathrm{R}$ & 0.9999 & 0.9997 \\
\hline
\end{tabular}

aqueous solution and the solid adsorbent can be determined by means of the immersion enthalpy of the solid in solutions that contain substances that interact with the surface and that allow the physicochemical properties of carbonized samples to be related to the adsorption capacity of the compounds that are in solution [13]. Figure 6 presents thermograms typical for of the immersion of carbonized bones in solutions of $\mathrm{Cu}^{2+}$ of $100 \mathrm{mg} \cdot \mathrm{L}^{-1}$, with the carbonized CHUOX shown in grey and the carbonized CHUN in black.

The values for the immersion enthalpies are proportional to the area under the curve of the peaks that are produced when a quantity of heat is generated due to the interaction between the solid and the solution. In this case it is observed that the first peak that corresponds to the immersion of the carbonized CHUOX in the solution of the ion copper is greater than that of the other peak, which indicates that the interaction is greater between solid and liquid and coincides with the greater adsorption obtained for the $\mathrm{Cu}^{2+}$ with carbonized sample as mentioned above.

Figure 7 shows the relation between the immersion enthalpy, $\Delta \mathrm{Him}$, of carbonized sample in the solution as a function of the maximum quantity adsorbed in the monolayer, $\mathrm{X}_{\mathrm{m}}$.

A linear trend is observed between both variables which indicate that the immersion enthalpy of carbonized sample in the ion solutions represents the energy that is released by the interaction between the solid and the liquid and constitutes a characterization parameter of the studied process.

\section{Conclusions}

Carbonized samples from bovine bones are prepared in nitrogen and air atmospheres and present surface areas of 170 and $130 \mathrm{~m}^{2} \cdot \mathrm{g}^{-1}$ and pore volumes of 0.07 and 0.06 $\mathrm{cm}^{3} \cdot \mathrm{g}^{-1}$ respectively. The carbonized samples are used as adsorbents for the $\mathrm{Cu}^{2+}$ and $\mathrm{Ni}^{2+}$ ions and adsorptions of 67.56 and $46.29 \mathrm{mg} \cdot \mathrm{g}^{-1}$ are obtained for the copper ion and 48.78 and $28.57 \mathrm{mg} \cdot \mathrm{g}^{-1}$ for the nickel ion; these adsorptions are related to the values of surface areas of the carbonized sample present.

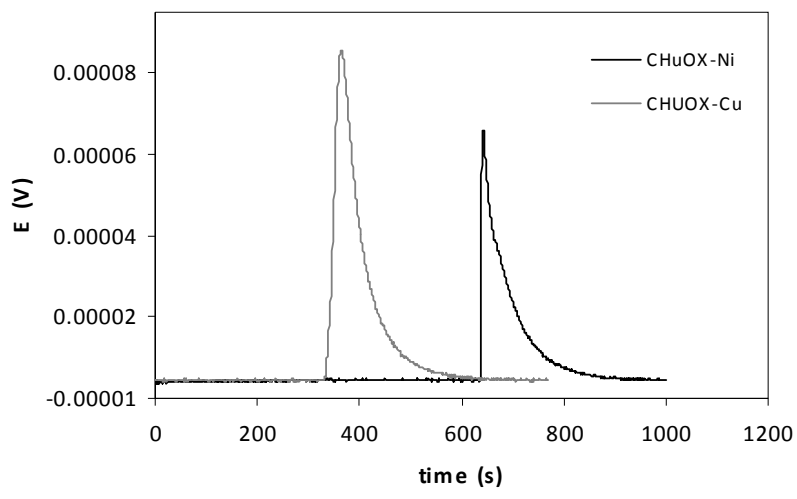

Figure 6. Calorimetric curves for the immersion of carbonized sample in solutions of $\mathrm{Cu}^{2+}$ of $100 \mathrm{mg} \cdot \mathrm{L}^{-1}$.

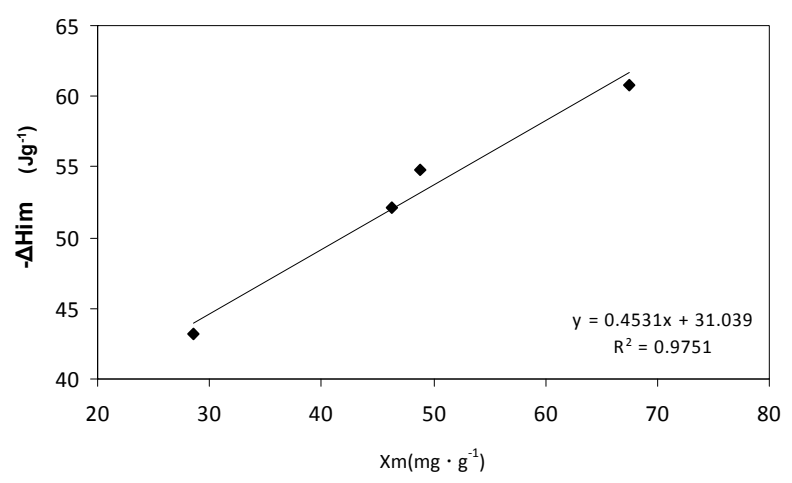

Figure 7. Immersion enthalpy as a function of the quantity adsorbed in the monolayer.

The immersion enthalpies of carbonized samples in solutions of $100 \mathrm{mg} \cdot \mathrm{L}^{-1}$ of both ions are determined and values between -43.16 and $-60.78 \mathrm{~J} \cdot \mathrm{g}^{-1}$ are found, indicating that the adsorption process is exothermic in both cases. The values of the immersion enthalpies are directly proportional to the values of the surface areas of the carbonized samples.

\section{Acknowledgments}

The authors wish to thank the Master Agreement established between the Universidad de los Andes and the Universidad Nacional de Colombia and the Memorandum of Understanding entered into by the Departments of Chemistry of both Universities.

\section{References}

[1] S. Al-Asheh, N. Abdel-Jabar and F. Banat, "Packed-Bed Sorption of Copper Using Spent Animal Bones: Factorial Experimental Design, Desorption and Columnregeneration," Advances in Environmental Research, Vol. 6, 2002, pp. 221-227. doi:10.1016/S1093-0191(01)00053-3

[2] M. Rao, A. V. Parwate and A. G. Bhole, "Removal of $\mathrm{Cr}^{6+}$ and $\mathrm{Ni}^{2+}$ from Aqueous Solution Using Bagasse and 
Fly Ash," Waste Manag, Vol. 22, 2002, pp. 821-830. doi:10.1016/S0956-053X(02)00011-9

[3] K. H. Keith and G. McKay, "Study of Arsenic (V) Adsorption on Bone Char from Aqueous Solution," Journal Hazard Mater, Vol. 160, No. 1, 2008, pp. 845-854.

[4] K. Chojnacka, "Equilibrium and Kinetic Modelling of Chromium (III) Sorption by Animal Bones," Chemosphere, Vol. 59, No. 3, 2005, pp. 315-320. doi:10.1016/j.chemosphere.2004.10.052

[5] M. Sitting, "Handbook of Toxic and Hazardous Chemicals," Noyes Publications, Park Ridge, New Jersey, 1981, pp. 876-932.

[6] M. C. Van der Leeden; F. L. Troise and D. K. Todd, "The Water Encyclopedia," $2^{\text {nd }}$ Edition, Lewis Publisbas, Michigan, 1990, pp. 876-998.

[7] D. Lima; C. Airoldi and K. K. Sousa, "Adsorption and Thermodynamic Studies of $\mathrm{Cu}(\mathrm{II})$ and $\mathrm{Zn}(\mathrm{II})$ on Organo Functionalized-Kaolinite," Applied Surface Science, Vol. 254, 2008, pp. 5157-5163. doi:10.1016/j.apsusc.2008.02.017

[8] Y. Ladino-Ospina; L. Giraldo and J. C. Moreno-Piraján, "Calorimetric Study of the Immersion Heats of Lead (II) and Chromium (VI) from Aqueous Solutions of Colombian Coffee Husk," Journal of Thermal Analysis and
Calorimetry, Vol. 81, No. 2, 2005, pp. 435-440. doi:10.1007/s10973-005-0803-6

[9] L. Giraldo and J. C. Moreno, "Calorimetric Determination of Activated Carbons in Aqueous Solutions," Journal of Thermal Analysis and Calorimetry, Vol. 89, No. 2, 2007, pp. 589-594. doi:10.1007/s10973-006-7524-3

[10] J. C. Moreno and L. Giraldo, "Determination of the Inmersion Enthalpy of Activated Carbon by Microcalorimetry of the Heat Conduction," Instrumentacion Science Technology, Vol. 28, No. 2, 2000, pp. 171-178. doi:10.1081/CI-100100970

[11] J. F. Porter and G. McKay, "Sorption Equilibria of Metal ions on Bone Char," Chemosphere, Vol. 54, No. 3, 2004, pp. 273-281. doi:10.1016/j.chemosphere.2003.08.004

[12] C. Kardirvelu, F. Brasquet and P. Le Cloirec, "Removal of $\mathrm{Cu}(\mathrm{II}), \mathrm{Pb}(\mathrm{II})$, and $\mathrm{Ni}(\mathrm{II})$ by Adsorption onto Activated Carbon Cloths," Langmuir, Vol. 16, No. 22, 2000, pp 8404-8409. doi:10.1021/la0004810

[13] D. A. Blanco; L. Giraldo and J. C. Moreno, "Effect of the $\mathrm{pH}$ in the Adsorption and in the Immersion Enthalpy of Monohydroxylated Phenols from Aqueous Solutions on Activated Carbons," Journal of Hazard Mater, Vol. 169, No. 1-3, 2009, pp. 291-296. doi:10.1016/j.jhazmat.2009.03.099 